\title{
Production of Medium Strength Self Compacting Concrete using Silica Fume and Quarry Dust
}

\author{
R.Chithra, K.Ramadevi, S.Chithra, R. Ravindranath Chandra, L. Mangaleshwaran
}

\begin{abstract}
Self Compacting Concrete (SCC) is able to compact under its own mass in thin sections and in congested reinforced zones due to its high fluidity and cohesiveness. In order to produce an eco-friendly self compacting concrete with characteristic compressive strength of 40MPa, a fine industrial by-product silica fume is used as a partial substitutefor cement by weight (5\%, $7.5 \%$ and $10 \%)$ and in addition to that quarry dust is partially replaced for natural fine aggregate from 5 to $15 \%$ with an increment of 5\%. To study the effect of silica fume and quarry dust in fresh and hardened properties of medium strength self compacting concrete, 10 different SCC mixes were designed using Japanese method. From the experimental studyit was observed that the SCC mix containing $7.5 \%$ silica fume and $5 \%$ quarry dust exhibits the equivalent properties as that of SCC mix made with conventional materials and found to be optimum. Also, analytical expressions are proposed to predict the indirect tensile strength and flexural strength of SCC in terms of compressive strength and the results are compared with the existing codal provisions.
\end{abstract}

Key Words: Eco-friendly, Self Compacting Concrete, Silica Fume, Quarry Dust, Fresh Properties, Mechanical properties.

\section{INTRODUCTION}

Increase in population in developing countries and rapid industrialization results in problems in disposal of industrial wastes and by-products which causes major issues in environment and ecological balance. As per research data, every year so many tons of quarry waste is produced during the production of coarse aggregate which is one of the main ingredients in concrete construction industry. Also, construction activities are increased manifolds to cater the need of increase in population. Such construction activities resulted in the depletion of natural resources like lime stone and river sand and points to the sustainability issues. [B. Felekoglu, 2008]. To overcome and manage these problems, industrial by products like quarry dust, silica fume etc., are utilized by the various researchers for the production of concrete [Ho. Et. al, 2002, M.Sonebi, 2004, G. Liu et. al, 2007].

Now-a-days Self Compacting Concrete occupies a unique place in the present construction sector due to its special self

Revised Manuscript Received on August 14, 2019.

R.Chithra, Department of Civil Engineering, Government College of Technology, Coimbatore - 641 013. T.N, India

K.Ramadevi, Department of Civil Engineering, Kumaraguru College of Technology, Coimbatore - 641 049. T.N, India

S.Chithra, Department of Civil Engineering, Government College of Technology, Coimbatore - 641 013. T.N, India

R. Ravindranath Chandra, Department of Civil Engineering, United Institute of Technology, Coimbatore - 641 020. T.N, India 600 025. T.N, India
L. Mangaleshwaran Directorate of Technical Education, Chennai -

consolidating behavior. It does not require vibration and compaction at the concrete construction sites [H. Okamura and M. Ouchi (1999), HAF. Dehwah. (2012), Ho et.al (2002) and I. Yadegran (2007)] which in turn reduces the construction speed as well as project cost. In urban areas, the use of SCC is more owing to its advantages like reduced noise level during casting and working conditions[M. Ouchi (2003) and M. Ouchi et.al (2003)].

Self consolidation of SCC could be achieved with high fluidity and cohesiveness. To achieve this cohesiveness, large amount of mineral fillers/powders like fly ash, crushed lime stone and silica fume are incorporated in SCC [B. Felekoglu (2003), M. Liu (2011) and B.Felekoglu et. al (2007)]

The limitation of the coarse aggregate content, reduction of maximum size of aggregates, and use of super plasticizer are the principles to obtain self-consolidation behavior inSCC [A. Sivakumar (2011), Ho et.al (2002), I. Yadegran (2007), K. A. Melo, and A. M. P Carneiro (2010)]. One of the consequences of reduction in coarse aggregate content was reported as it increases the mortar content in the mixture. Due to increased paste volume, the powder content in SCC is considerably high compared to conventional concrete. High cement content may lead to problems like rise in shrinkage potential, construction cost, and heat of hydration in concrete. On another point of view, increase in the mortar content makes a better quality of SCC which inturn results in some technical troubles. Therefore, to solve a part of these problems,powder was introduced which includes coal fly ash, limestone powder, silica fume, calcinated clays, ground glass and blast furnace slag [G. Liu (2007), H. J. H. Brouwers and H. J. Radix (2005) and K. H. Khayat et.al (2004)].

The main objective of this work is to produce eco-friendly sustainable Self Compacting Concrete using industrial waste products, such as, silica fume and quarry waste. In this study, silica fume which is a by-product from production of silicon metals and ferro silican alloys is used as a partial substitute material for cement. Cement is replaced by silica fume by $5 \%, 7.5 \%$ and $10 \%$ by weight of cement and the quarry dust is used as fine aggregate replacement material in $5 \%, 10 \%$ and $15 \%$ by weight. The influence of silica fume and quarry dust in the performance and behaviour of SCC is experimentally evaluated. From the experimental study, 


\section{PRODUCTION OF MEDIUM STRENGTH SELF COMPACTING CONCRETE USING SILICA FUME AND QUARRY DUST}

analytical study is conducted to co-relate the mechanical properties of SCC containing silica fume and quarry dust.

\section{MATERIAL PROPERTIES}

Ordinary Portland Pozzolana cement of 53 grade was used in this study.Natural river sand conforming to zone II and specific gravity 2.68 was used as conventional fine aggregate. Maximum size of coarse aggregate used is $10 \mathrm{~mm}$ to avoid blocking effect with a specific gravity of 2.73. Potable water used for drinking purpose is used for mixing and curing the concrete.

Silica Fume also known as micro silica is used as a pozzolanic material in this study. It has a specific gravity of 2.2. Quarry dust is a fine aggregate replacement material having a specific gravity of 2.63 and conforming to Zone II.Master Glenium SKY 8233 is the super plasticizer used in this work.

\section{MIX PROPORTIONING}

In this study, a mix ratio of 1:1.78: 1.33:0.35 was arrived using Japanese method with the constant w/p ratio of 1.1 for SCC mixes.SCC requires the optimum amount of powder content and super plasticizers. The powder content can be achieved by fixing the percentage of coarse aggregate in the volume of concrete. The optimum super plasticizer dosage is arrived as $1 \%$ by weight of cement in trial and error basis. The dosage of super plasticizer, Master sky Glenium 8233 beyond $1 \%$ of mix proportion affects the strength. The cement content is partially replaced by silica fume for $5 \%$, $7.5 \%$ and $10 \%$ by weight. The fine aggregate is replaced by quarry dust for $5 \%, 10 \%$ and $15 \%$. The details of the mix proportions for the 10 combination of SCC mixes are presented in Table 1.Test methods for SCC

\begin{tabular}{|l|l|l|l|l|l|l|l|l|}
\hline S.No & Mix ID & $\begin{array}{l}\text { Cement } \\
\left(\mathrm{kg} / \mathrm{m}^{3}\right)\end{array}$ & FA $\left(\mathrm{kg} / \mathrm{m}^{3}\right)$ & CA $\left(\mathrm{kg} / \mathrm{m}^{3}\right)$ & Water $(\mathrm{l})$ & $\mathrm{SP}(\%)$ & $\mathrm{S}\left(\mathrm{kg} / \mathrm{m}^{3}\right)$ & $\mathrm{Q}\left(\mathrm{kg} / \mathrm{m}^{3}\right)$ \\
\hline 1. & CC & 537.24 & 959.86 & 719.85 & 187.6 & 1 & 0 & 0 \\
\hline 2. & S05Q05 & 510.38 & 911.87 & 719.85 & 187.6 & 1 & 26.86 & 47.99 \\
\hline 3. & S05Q10 & 510.38 & 863.87 & 719.85 & 187.6 & 1 & 26.86 & 95.99 \\
\hline 4. & S05Q15 & 510.38 & 815.88 & 719.85 & 187.6 & 1 & 26.86 & 143.99 \\
\hline 5. & S7.5Q05 & 496.95 & 911.87 & 719.85 & 187.6 & 1 & 40.29 & 47.99 \\
\hline 6. & S7.5Q10 & 496.95 & 863.87 & 719.85 & 187.6 & 1 & 40.29 & 95.99 \\
\hline 7. & S7.5Q15 & 496.95 & 815.88 & 719.85 & 187.6 & 1 & 40.29 & 143.99 \\
\hline 8. & S10Q05 & 483.52 & 911.87 & 719.85 & 187.6 & 1 & 53.72 & 47.99 \\
\hline 9. & S10Q10 & 483.52 & 863.87 & 719.85 & 187.6 & 1 & 53.72 & 95.99 \\
\hline 10. & S10Q15 & 483.52 & 815.88 & 719.85 & 187.6 & 1 & 53.72 & 143.99 \\
\hline \multicolumn{7}{|l|}{ Where FA - Fine aggregate; CA - Coarse aggregate; SP - Super plasticizer; S - Silica fume ; Q - Quarry dust. } \\
\hline
\end{tabular}

Table 1Mix Proportions

\subsection{Fresh Properties}

The performance of SCC in the fresh stage is specified by its passing ability, filling ability and segregation resistance. The fresh properties can be evaluated using slump flow, Jring, V-funnel and L-box test [EFNARC (2002), K. H. Khayat (1999)]. Fig.1 shows some of the workability tests as per EFNARC guidelines.

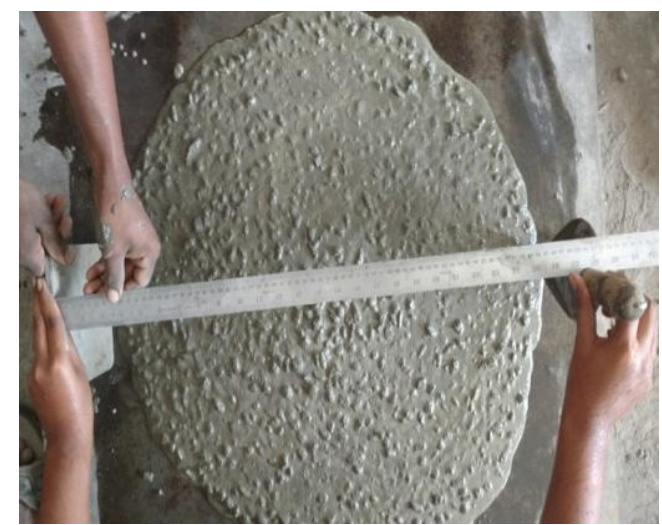

(a) 


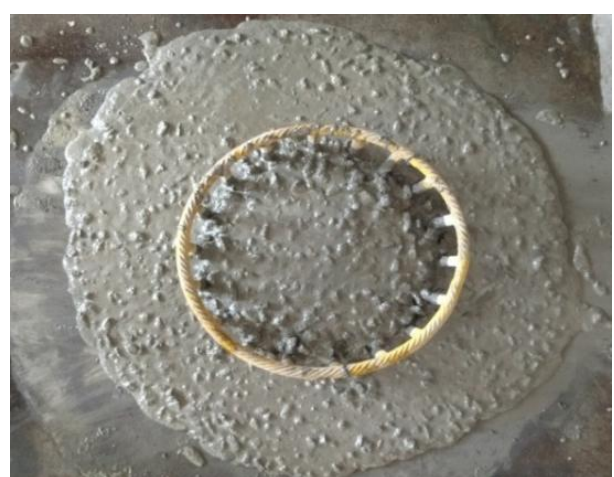

(b)

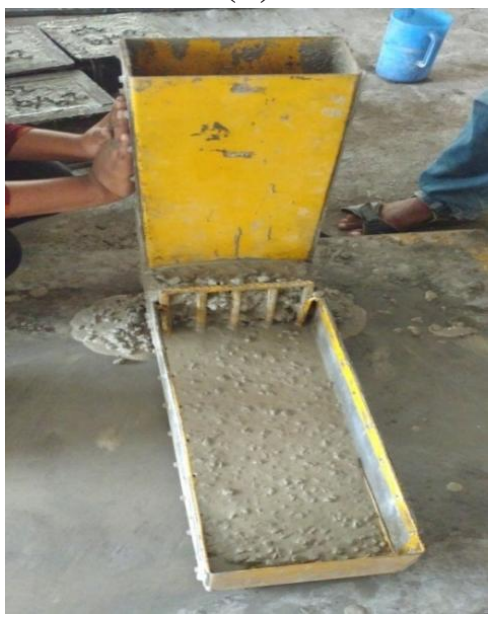

(c)

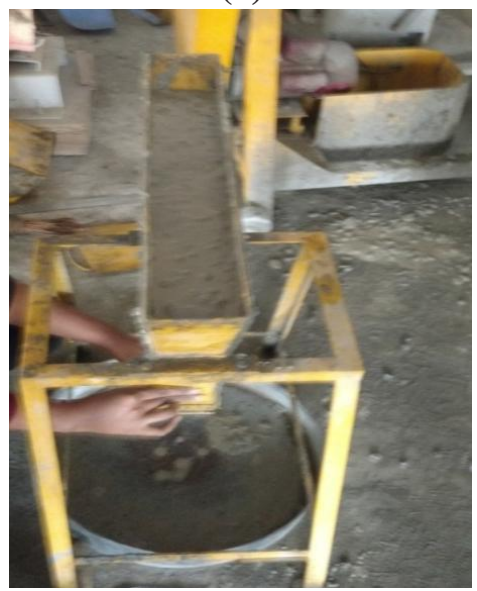

(d)

Fig.1. Workability tests (a) Slump flow test,(b) J ring test, (c) $\mathrm{L}$-box test,(d) $\mathrm{V}$-funnel test

\subsection{Hardened Properties}

For each test, 3 specimens with same mix proportions were used and the average of such results is presented here. Water curing was done for all the specimens, 48 hours after casting. Compressive Strength was determined at 7 and 28 days curing in $100 \mathrm{~mm}$ size cubes. Cube specimens were tested in digital compression testing machine of $300 \mathrm{~T}$ capacity. $100 \mathrm{~mm}$ diameter and $200 \mathrm{~mm}$ high cylindrical specimenswere used to predict the splitting tensile strengthafter 28 days. Young's modulus was evaluated after 28days of curing in cylindrical specimens of $150 \mathrm{~mm}$ diameter and $300 \mathrm{~mm}$ height. The flexural strength was evaluated in a standard two point loading test by using 100 $\mathrm{mm}$ x $100 \mathrm{~mm}$ x $500 \mathrm{~mm}$ prismatic concrete specimens. All the tests were conducted according to IS 516:1959.

\section{RESULTS AND DISCUSSIONS}

The properties of self compacting concrete with silica fume and quarry dust replacements were found out and the test results with detailed discussions are given below.

\subsection{Fresh properties of SCC}

Fresh concrete properties of SCC containing silica fume and quarry dust arediscussed in this section. In this study, all the 10 mixes satisfy the workability requirements as per EFNARC guidelines.

The variation of slump-flow and the J-ring values for all SCC mixes are demonstrated in Fig. 2. The minimum slump flow requirement as per EFNARC guidelines is $650 \mathrm{~mm}$. From Fig. 2, it is noted that the mix S7.5Q05 is more workable with a slump flow of $700 \mathrm{~mm}$, whereas S05Q15 possess least flow of $655 \mathrm{~mm}$. Fig. 4 shows the variation in slump flow with quarry dust for constant silica fume content. From the figure it is noted that increase in quarry dust tends to reduce the flowability of SCC mixes. This could be due to higher water absorption capacity of quarry dust. Even though the slump flow gets decreased with the increase in quarry dust percentage, the value does not fall below the slump flow of conventional mix CC except S05Q15 mix.

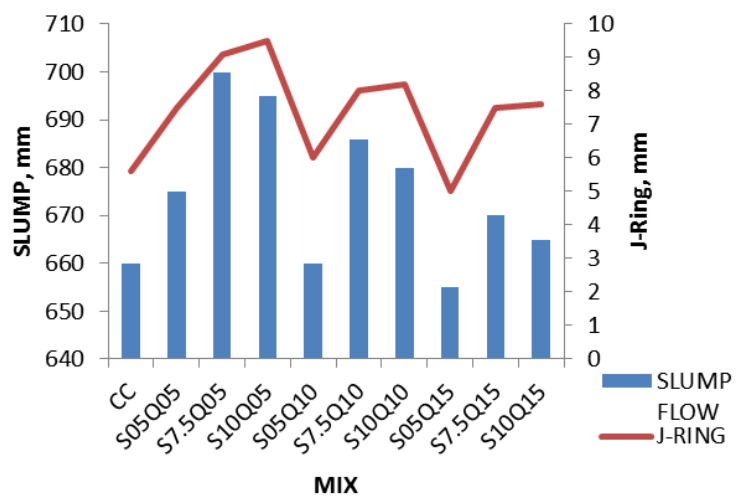

Fig.2.Variation of slump flow and J-Ring results

It was found that silica fume adsorbs some superplasticizer on its surface due to its finer particle size and quarry dust has lower stiffness when compared to silica fume and this decreases the flowability hence affecting the workability of the mix.

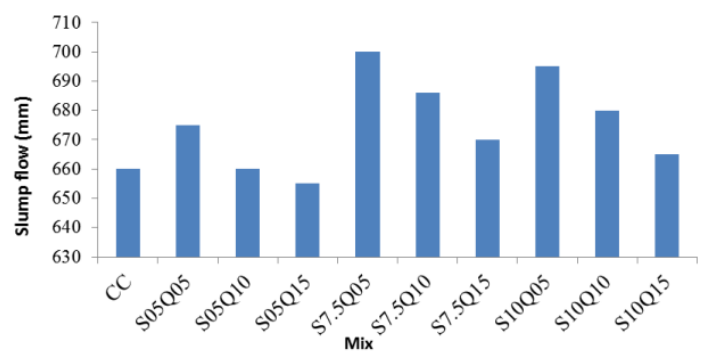

Fig. 3. Variation of slump flow with \% of quarry dust

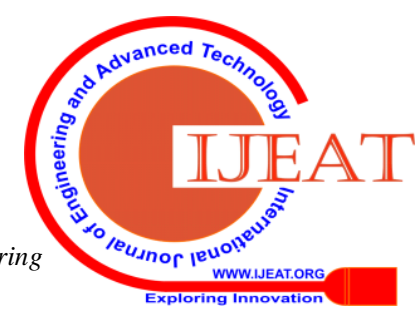




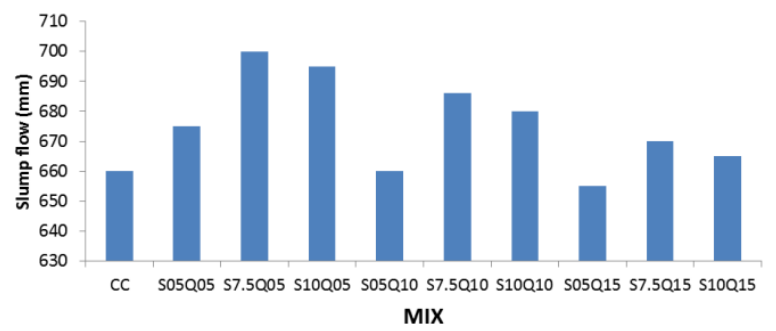

Fig. 4. Variation of slump flow with $\%$ of silica fume

As shown in Fig. 4, it is observed that silica fume tends to improve the flowing ability whereas quarry dust reduces flowability in the mixes. Also, it is seen from the graph that upto $7.5 \%$ of silica fume, the slump flow and J-ring value increases. After that, there is a gradual decrease in the flowability.

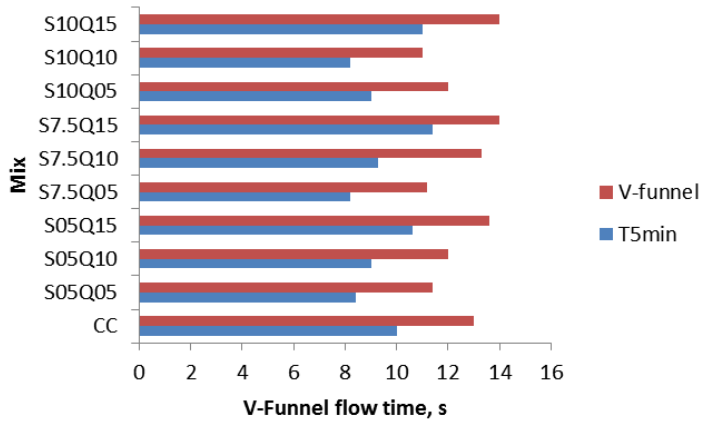

Fig. 5.Variation of V-funnel and T5min results

Fig. 5 shows, variation of $\mathrm{V}$-funnel times and $\mathrm{T}_{5 \min }$ of all SCC mixtures.From the figure, it is observed that all the mixes are in satisfactory range of 8-12 s. It shows that all the mixes have good filling ability. The time taken is increased when the quarry dust percentage is increased.This could be due to the density and water retention property of quarry dust. This drawback of quarry dust is compensated bysilica fume, which has shown good results in improving

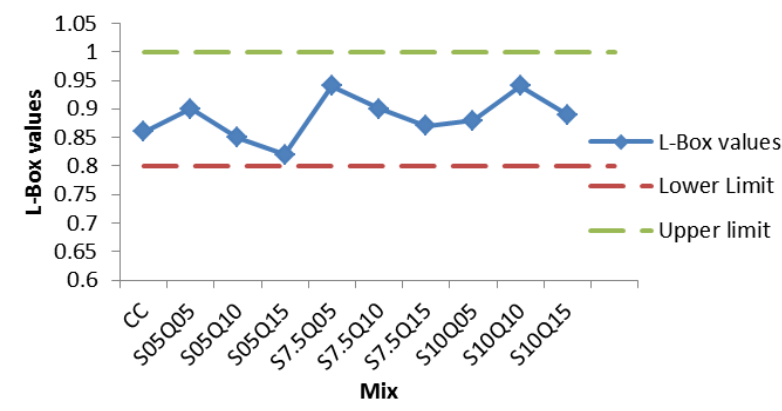

Fig. 6.Variation of L-box testresults

The L-box values which indicate the blocking ratios are given in Fig.6. The L-box values of all mixes are between the EFNARC guideline's target ranges 0.8 to 1 . Almost all mixes shows higher L-box ratios compared to the CC, except S05Q15. When quarry dust percentage increased, the block ratio also increased due to the reduced viscosity of SCC mix caused by the water absorption of quarry dust [Uysal M, 2012]. workability properties.

\subsection{Hardened concrete properties of SCC}

\subsubsection{Strength properties}

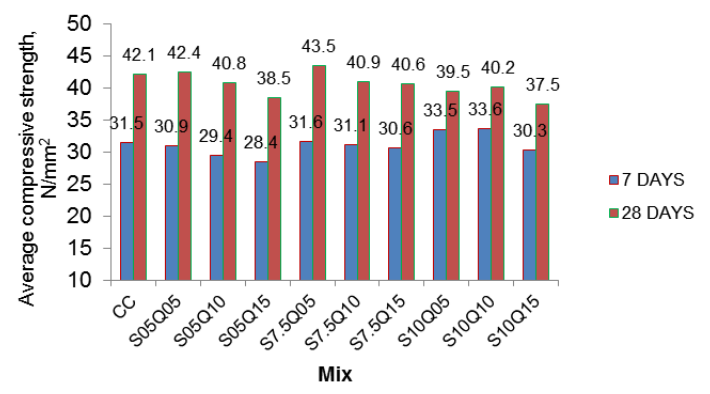

Fig.7. Variation of compressive strength

Fig. 7 shows the average compressive strengths values at 7 days and 28 days. It is noted that the compressive strength linearly decreases for the mixes S05Q05, S05Q10 and S05Q15. It implies that in SCC mixes with 5\% silica fume, a linear decrease in compressive strength is observed due to the increase in quarry dust percentage of $5-15 \%$ with the increment of $5 \%$. Similarly, the same trend of results were observed for the next three mixes S7.5Q05, S7.5Q10 and S7.5Q15 but the compressive strength for S7.5Q05 increased at about 3.3\% from CC. It was understood that silica fume has enhanced cement hydration as a result of which the strength has increased. For the remaining mixes S10Q05, S10Q10 and S10Q15 a decreasing trend is observed. The highest compressive strength was noted in S7.5Q05 while S10Q15 mix had the lowest value. The compressive strength of S05Q10, S7.5Q10, S7.5Q15 and S10Q10 was almost the same. The increase in compressive strength in mixes containing $5 \%$ and $7.5 \%$ silica fume is due to the pore filling effects of silica fume.

From these values, the optimum percentage of silica fume and quarry dust in strength aspect is found to be $7.5 \%$ and $5 \%$ respectively. Beyond $7.5 \%$, with increase in percentage ofsilica fume, the compressive strength was found to have decreasing pattern and this may be due to the presence of unreacted hydration products of silica fume with voids. Obviously, the increase in percentage of silica fume increases the water requirement,forming more number of voids and there is a drop in the strength after attaining the optimum conditions[Memon et. al, 2013]. Even though, the compressive strength enhancement of $1 \%$ and $3.3 \%$ was observed for the mixes S05Q05 and S7.5Q05, comparing to the conventional concrete $\mathrm{CC}$.

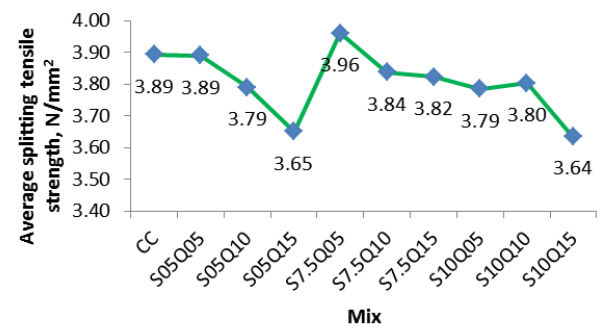

Fig. 8.Variation of splitting tensile strength at 28 days

Published By: Blue Eyes Intelligence Engineering 
Fig. 8 shows the variation in splitting tensile strengths values at 28 days. The splitting tensile strengths almost exhibit the similar trend as that of the compressive strength. The splitting tensile strength of S7.5Q05 was the highest while it was the lowest in S10Q15 mixes with the values of $3.96 \mathrm{~N} / \mathrm{mm}^{2}$ and $3.64 \mathrm{~N} / \mathrm{mm}^{2}$ respectively. The splitting tensile strength of S05Q05 and CC was almost the same. The splitting tensile strength of S05Q05 S7.5Q10, S7.5Q15 and S10Q10 were almost the same. The increase in percentage of tensile strength of S7.5Q05 was found to be $4.04 \%$ more than the CC.

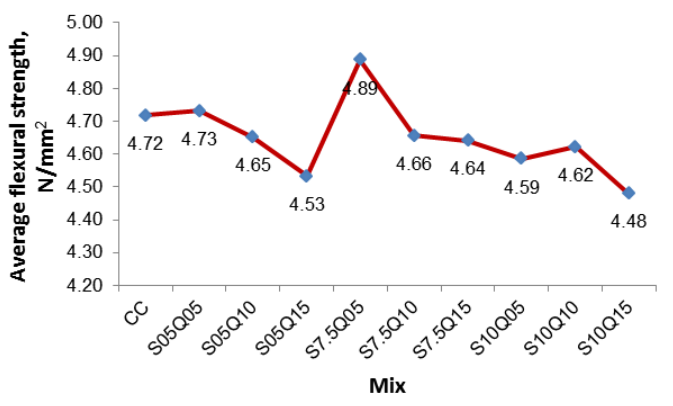

Fig. 9. Variation of flexural strength at 28 days

Fig.9shows the average flexural strengths values at 28 days. The flexural strengths almost follow the similar pattern as the compressive strength does. The flexural strength is highest in S7.5Q05 while it is the lowest in S10Q15 mixes. The flexural strength of S05Q10, S7.5Q10, S7.5Q15 and S10Q10 was almost the same. The increase in percentage of flexural strength for $\mathrm{S} 7.5 \mathrm{Q} 10 \mathrm{mix}$ is $3.5 \%$ than the CC.

\subsubsection{Initial tangent modulus}

The uniaxial compression test of cylinders is carried out to determine the initial tangent modulus. Fig. 10 shows the trend of compressive strength with modulus of elasticity of all mixes.

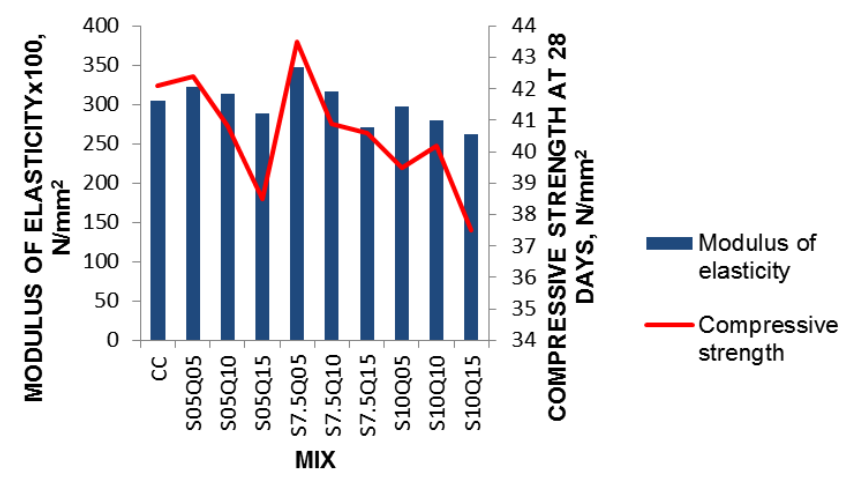

Fig.10.Variation of Compressive strength and Modulus of elasticity

From the figure it is noted that there is an increase in modulus of elasticity when the compressive strength increases. This could be due to the fact that the stiffness of concrete mix with quarry dust gets decreased which inturn decreases the modulus of elasticity. The highest value is found in S7.5Q05 whereas S10Q15 has the lowest value.

\subsubsection{Relationship between the mechanical properties of concrete}

The relation between compressive strength and split tensile strengthof SCC mixes containing silica fume and quarry dust is shown in Fig. 11. Fig. 12, shows the relation between compressive and flexural strength. The $\mathrm{R}^{2}$ value of the plot is greater than 0.9 , which exhibits a good correlation between the strength properties.

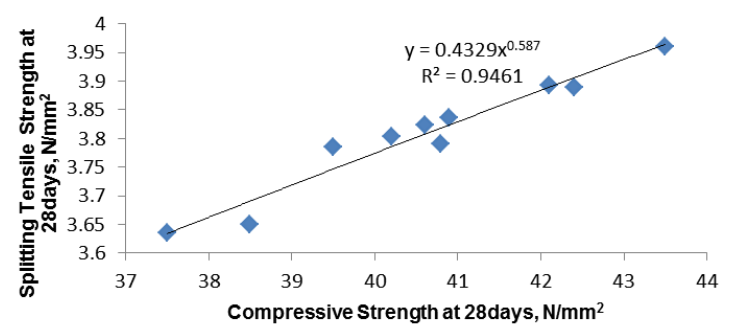

Fig.11.Compressive strength Vs splitting tensile strength

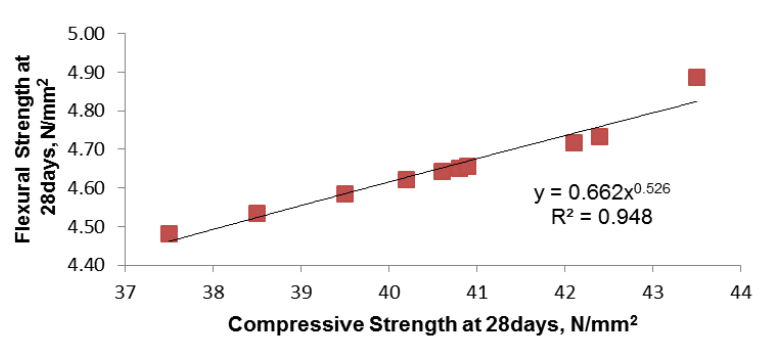

Fig.12.Compressive strength Vs Flexural strength

From Figure 13, it is noted that the ratio of the splitting tensile to the compressive strengths were mostly influenced by their compressive strengths, as the ratio decreased with increasing compressive strength; which justifies the findings of Arioglu et al. (2006). From the line plot, it is seen that the ratio of splitting tensile strength to compressive strength varies from 0.091-0.097.

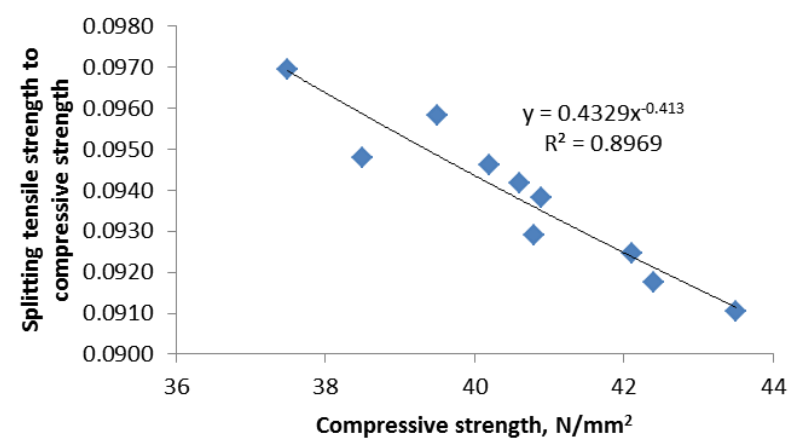

Fig. 13.Ratio of splitting tensile to compressive strength Versus compressive strength

\subsubsection{Prediction of mechanical properties using existing} models

In this section, indirect tensile strength and flexural strength are predicted using the equations proposed in 


\section{PRODUCTION OF MEDIUM STRENGTH SELF COMPACTING CONCRETE USING SILICA FUME AND QUARRY DUST}

section 5.2.3 and the values are compared with the existing codal provisions shown in Table 2.The results of the predicted strengths of concrete for the models considered in this study are presented in figures 14 and 15 .

Table 2Estimating Models Details

\begin{tabular}{|c|c|c|}
\hline $\begin{array}{l}\text { Mechanical } \\
\text { property }\end{array}$ & Source & Estimating Models \\
\hline \multirow{5}{*}{$\begin{array}{l}\text { Indirect } \\
\text { tensile } \\
\text { strength }\end{array}$} & ACI 363R-08 & $f_{c t, s p}=0.59 \sqrt{f_{c m}}$ \\
\hline & $\mathrm{EC}-2$ & $f_{c t, s p}=\frac{1}{3}\left(f_{c m}-8 M p a\right)^{\frac{2}{3}}$ \\
\hline & NZS 3101:2006 & $f_{c t, s p}=0.54 \sqrt{f_{c m}}$ \\
\hline & CSA A23.3-04 & $f_{c t, s p}=0.67 \sqrt{f_{c m}}$ \\
\hline & $\begin{array}{l}\text { PROPOSED } \\
\text { MODEL (CM) }\end{array}$ & $f_{t}=0.432 f_{c u}^{0.587}$ \\
\hline \multirow{6}{*}{$\begin{array}{l}\text { Modulus of } \\
\text { rupture }\end{array}$} & ACI 363R-08 & $f_{c f t}=0.94 \sqrt{f_{c m}}$ \\
\hline & EC-2 & $\begin{array}{l}f_{c t f t}=0.43\left(f_{c m}-\right. \\
8 M p a 23\end{array}$ \\
\hline & NZS 3101:2006 & $f_{c f t}=0.8 \sqrt{f_{c m}}$ \\
\hline & CSA A23.3-04 & $f_{c f t}=0.6 \sqrt{f_{c m}}$ \\
\hline & IS 456-2000 & $f_{c f t}=0.7 \sqrt{f_{c k}}$ \\
\hline & $\begin{array}{l}\text { PROPOSED } \\
\text { MODEL (CM) }\end{array}$ & $f_{f}=0.662 f_{c u}^{0.526}$ \\
\hline
\end{tabular}

Where,

$f_{c k}=$ Characteristic compressive strength of concrete at 28 days, $\mathrm{MPa}$

$f_{c m}=$ Mean compressive strength of concrete at 28 days, $\mathrm{MPa}$ $\mathrm{MPa}$

$f_{c f t}, f_{f}=$ Modulus of rupture of concrete at 28 days, $\mathrm{MPa}$

$f_{\text {ctft }}=$ Modulus of rupture of concrete at 28 days (EC2), $\mathrm{MPa}$

$f_{c u}=$ Cube compressive strength of concrete at 28 days, $\mathrm{MPa}$

From the plots, it is shown that thepredicted values of splitting tensile strength were not significantly different from the experimental values for all the tested models. The EC, NZS and proposed model estimates the splitting tensile strength that is nearly closest to the experimental value for the range of concrete compressive strengths considered in this research. $f_{c t, s p}=$ Indirect tensile strength of concrete at 28 days,

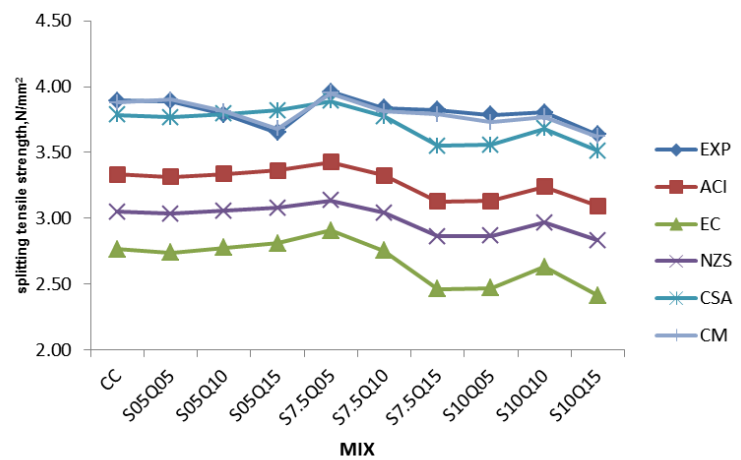

Fig. 14.Line plot of splitting tensile strength calculatedfrom various models

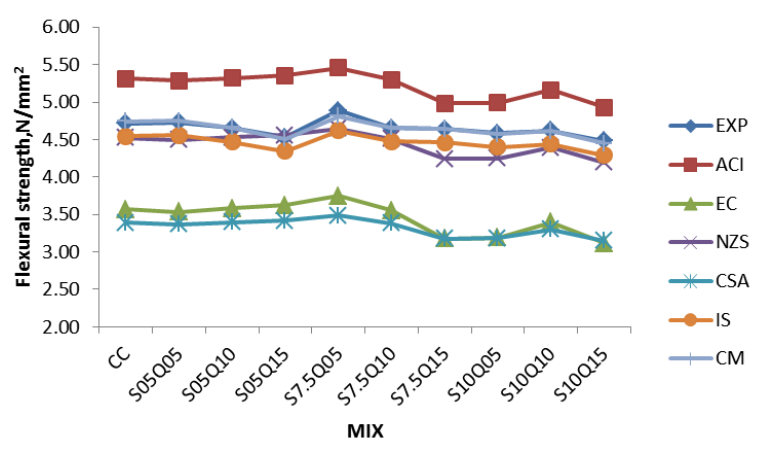

Fig. 15.Line plot of flexural strength calculatedfrom various models

Based on the results from fig. 16, the NZS, IS and CM models are closer with the experimental values. The ACI model overestimates and the CSA and EC models underestimate the results of flexural strength in this study.

\section{CONCLUSIONS}

In this study, an eco-friendly SCC mix was arrived using Japanese method with silica fume and quarry dust. From the experimental study, the following conclusions were drawn:

All mixtures exhibited good workability with improved passing and filling abilities. The results obtained from the workability tests showed that those are within the limits specified by EFNARC guidelines.

$>$ The fineness of Silica fume played a vital role in improving the flowability properties of SCC whereas quarry dust acts as a filler material. Hence, the presence of silica fume in SCC shows the better workability properties.

> The compressive strength enhancement of $1 \%$ and $3.3 \%$ was observed for the mixes S05Q05 and S7.5Q05, compared to the conventional concrete CC. The increase in percentage of tensile strength of S7.5Q05 was found to be $4.04 \%$ more than the CC. The marginal increase in percentage of flexural strength of S7.5Q10 was found to be $3.5 \%$ than the CC. 
When the percentage of silica fume is increased beyond $7.5 \%$, the compressive strength is found to decrease and this may be due to increase in voids present in coarse aggregate matrix formed by unhydrated silica fume.

$>$ The compressive strength tends to decrease when the percentage of quarry dust is increased with constant silica fume content. Here, the quarry dust acts as an inert material. When the replacement percentage is increased beyond $5 \%$, the strength properties are reduced.The splitting tensile strengths and flexural strength almost follows the same trend as the 28- day compressive strength does.

$>$ The optimum level of addition of silica fume and quarry dust was found to be $7.5 \%$ and $5 \%$ by weight of cement and fine aggregate respectively.

$>$ The ratio of splitting tensile strength to compressivestrengths decreased with increasingcompressive strength and was found to be in the range of 0.091-0.097.

$>$ A good correlation was observed between the specific strength properties.

$>$ The EC and NZS models predict splitting tensile strengths that is closest to the experimental value for the range of concrete compressive strengths considered in this research.

$>$ The model NZS and IS predicts flexural strengths that is near closest to the experimental value for the range of concrete compressive strengths considered in this research.

\section{REFERENCES}

1. A. Sivakumar, G. Elumalai, and V. Srinivasan, A conceptual approach of the mixing proportion technique for producing self compacting concrete, Journal of Civil Engineering and Construction Technology, vol. 2, pp. 65-71, 2011.

2. ACI Committee 318, Building Code Requirements for Structural Concrete and Commentar, American Concrete Institute, Farmington Hills, MI, pp. 107, 2014.

3. American Concrete Institute ACI 318-08, Building code for structural concrete, Detroit, USA, 2008.

4. American Concrete Institute. ACI 363R-08, State of the art report on high strength concrete. Detroit, USA, 2008.

5. B. Felekoglu, , S.Turkel and B.Baradan, Effect of water/cement ratio on the fresh and hardened properties of self compacting concrete,Building and Environment, Vol. 42, pp. 1795 -1802, 2007.

6. B. Felekoglu, Investigation on mechanical and physical properties of SCC, M.Sc. Thesis in Civil Engineering, Dokus Eylul University, Izmir, 2003.

7. B. Topcu, and T. Uygunoglu , Influence of mineral additive type on slump-flow and yield stress of self consolidating mortar, Scientific Research and Essays, vol. 5, pp. 1492-1500, 2010.

8. B. Felekoglu, A comparative study on the performance of sands rich and poor in fines in self-compacting concrete. Construction and building materials, Vol. 22, pp. 646-654, 2008.

9. C. Jianxiong, P. Xincheng and H. Yubin, A study of selfcompacting HPC with superfine sand and pozzolanic additives, Proceedings of the First International RILEM Symposium , 1999, 549-560.

10. CSA Technical Committee. Reinforced Concrete Design. A23.3-04(2004), Design of concrete structures, Rexdale, Ontario. Canadian Standards Association.
11. EFNARC, Specifications and Guidelines for SelfCompacting Concrete, EFNARC, UK (www.efnarc.org), pp. 1-32, 2002.

12. European Standard. European committee for standardization, Eurocode 2: Design of concrete structures

13. G. Liu, Ye, X. Schutter, G.D. Poppe, A.-M. and L. Taerwe, Influence of limestone powder used as filler in SCC on hydration and microstructure of cement pastes, Cement and Concrete Composites, 29, 2007, 94-102.

14. G. Moriconi, and V.Corinaldesi, Durable fiber reinforced self compacting concrete, Cement and concrete research, Vol... 34, pp.249-254, 2004.

15. H. J. H. Brouwers and H. J. Radix, Self-compacting concrete: the role of the particle size distribution, First international symposium on design, performance and use of self-consolidating concrete SCC 2005- Changsha, Hunan, China, pp. 109-118, 2005.

16. H. Okamura and M. Ouchi, Self-compacting concrete: development, present use and future, Proceedings of the First International RILEM Symposium, 3-14, 1999.

17. HAF. Dehwah, Mechanical Properties of SelfCompacting Concrete Incorporating Quarry Dust Powder, Silica Fume or Fly Ash, Construction and Building Materials, pp. 547-551, 2012.

18. Ho, D.W.S., Sheinn, A.M.M., Ng, C.C. and Tam C.T. The use of quarry dust for SCC applications, Cement and Concrete Research, 32, 2002, 505-511.

19. I. Yadegran , M. Mahoutian, M. Shekarchi and N. A. Libre, Effect of polypropylene fibers on shrinkage of self compacting concrete, in Proceedings of the 5th International RILEM Symposium on Self Compacting Concrete, pp. 707-713, Gent, Belgium, September 2007.

20. K. A. Melo, and A. M. P Carneiro, Effect of metakaolin finesses and content in self-consolidating concrete, Construction and Building materials, Vol. 24, pp. 1529. $1535,2010$.

21. K. H. Khayat, J. Assaad and J. Daczko Comparison of field-oriented test methods to assess dynamic stability, ACI Materials Journal, 101(2), pp:168-176, 2004.

22. K. H. Khayat, Workability, testing, and performance of self consolidating concrete, ACI Materials Journal, vol. 96, no. 3,pp. 346-353, 1999.

23. Rajendran, Arunkumar, Nagaraj Balakrishnan, and Mithya Varatharaj. "Malleable fuzzy local median C means algorithm for effective biomedical image segmentation." Sensing and Imaging 17, no. 1 (2016): 24.

24. K. Johansen and T. A. Hammer, Drying Shrinkage of Norwegian Self-Compacting Concrete, SINTEF Trondheim (2002).

25. K. M. A. Hossain and M. Lachemi, Bond behavior of self consolidating concrete with mineral and chemical admixtures, Journal of Materials in Civil Engineering, vol. 20, no. 9, pp. 608-616, 2008.

26. Kunlin Ma, Jin Feng, Guangcheng Long, Youjun Xie, Xiaobo Chen,Improved mix design method of selfcompacting concrete based on coarse aggregate average diameter and slump flowConstruction and Building Materials, 143,566-573, 2017.

27. M. Bignozzi, and Sandrolini, Tyre rubber waste recycling in self compacting concrete Cement and concrete research, Vol. 36, pp. 735-739, 2006.

28. M. Liu, Incorporating ground glass in self-compacting concrete, Construction and Building Materials, vol. 25, no. 2, pp. 919-925, 2011.

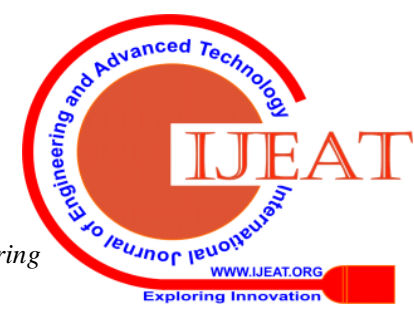


29. M. Ouchi, Applications of self compacting concrete in Japan, Europe and the United States. Kochi University of Technology, Kochi, Japan; 2003.

30. M. Ouchi, S. Nakamura, T. Osterson, S. Hellberg, M. Lwin, Applications of self compacting concrete in Japan. Europe and the United States, ISHPC; 2003. p. 1-20.

31. M. Sari, Prat, and E. J.F. Labastire, High strength selfcompacting concrete-original solutions associating organic and inorganic admixtures, Cement and Concrete Research, 29, 1999, 813-818.

32. M. Sonebi, Medium strength self-compacting concrete containing fly ash: Modelling using factorial experimental plans. Cement and concrete research, Vol. 34, pp. 1199-1208, 2004.

33. N. Arioglu, Z.C.Girgin, E. Arioglu, Evaluation of ratio between splitting tensile strength and compressive strength for concretes up to $120 \mathrm{MPa}$ and its application in strength criterion, ACI Materials Journal 103 (1), (2006), 18-24.

34. New Zealand Standard. Concrete structures standard. NZS 3101:2006. "The design of concrete structures", Wellington, New Zealand.

35. O. Boukendakdji, S. Kenai, E. H. Kadri and F. Rouis, Effect of slag on the rheology of fresh self compacted concrete, Construction and Building Materials, vol. 23, no. 7, pp. 2593-2598, 2009.

36. PL. Domone, HW. Chai, J. Jin Optimum mix proportioning of self-compacting concrete. In: Dhir RK, Jones MR, editors. Proceeding on international conference on innovation in concrete structures: design and construction. London: University of Dundee, Thomas Telford, p. 277-85, 2009.

37. R. Ince, and K. E.Alyamac, A preliminary concrete mix design for SCC with marble powders, Construction and building materials, Vol.23, pp. 1201-1210, 2009.

38. Reza Bani Ardalan, Alireza Joshaghani, R. Douglas Hooton, Workability retention and compressive strength of self compacting concrete incorporating pumice powder and silica fume,Construction and Building Materials, 134, 116-122, 2017.

39. Wang, C. Druta, Lane, D. S. Tensile strength and pasteaggregate bonding characteristics of self-consolidating concrete. Construction and Building Materials, v. 55, p. 89-96, 2014.

40. Y. Xie, B. Liu, J. Yin And S. Zhou, Optimum mix parameters of high-strength self-compacting concrete with ultrapulverized fly ash. Cement and concrete research, Vol. 32, pp. 477-480, 2002.

41. M.Uysala, K. Yilmaz and M. Ipek, The effect of mineral admixtures on mechanical properties, chloride ion permeability and impermeability of self-compacting concrete, Construction and Building Materials, Volume 27, Issue 1, 2012, pp: 263-270.

42. F. A. Memon, M. F. Nuruddin and N. Shafiq, Effect of silica fume on the fresh and hardened properties of fly ash-based self-compacting geopolymer concrete, International Journal of Minerals, Metallurgy, and Materials, 2013, Volume 20, Issue 2, pp 205-213. 